\title{
RECONSTRUYENDO EL CONSTRUCTIVISMO: HACIA UN MODELO EVOLUCIONISTA DEL APRENDIZAJE DE CONCEPTOS
}

\author{
LUFFIEGO GARCÍA, MÁXIMO \\ IES La Albericia. Av. Deporte s/n. 39012. Santander.
}

\begin{abstract}
SUMMARY
In this article we are presented one point of view about the two debates opened up in this journal: those of constructivism and of conceptual change. This article sets forth the formulation of a kind of constructivism based on a systemic and evolucionist perspective, a constructivism which assumes the objectivity of knowledge and which rejects any relativist positions. Hence we have the basis of an evolutionist method in the concept-learning process which explains in a plausible, simple way some essential questions of the so called conceptual change. Finally, based on this model, a few contributions have been made in the field of teaching strategies and methods, as well as an analysis of those already in existence.
\end{abstract}

\section{INTRODUCCIÓN}

En el presente artículo se pretende reflexionar en torno al paradigma constructivista considerando tres perspectivas que han estado presentes en los debates mantenidos sobre el cambio conceptual y el constructivismo en esta revista en el año 1999: la epistemológica, la psicológica y la educativa.

Aunque se puede discutir la oportunidad de abrir un debate de los fundamentos filosóficos y epistemológicos del constructivismo, desde la didáctica de las ciencias no se puede negar la legitimidad y conveniencia de hacerlo, por dos motivos esencialmente: en primer lugar, para participar en la construcción de un contexto transdisciplinar que favorezca el desarrollo de la didáctica de las ciencias, dotando de unidad a la misma, ahora que, como resultado de su consolidación y crecimiento, comienza a experimentar procesos de diferenciación; y, en segundo lugar, para justificar el papel que ha de ocupar la ciencia en una educación que asume como objetivo «la ciencia para todos» pero que, al mismo tiempo, se halla desorientada por la marejada postmoderna y relativista que nos envuelve y que cuenta con ardorosos partidarios en el seno mismo del movimiento constructivista.

Desde nuestro punto de vista, las concepciones sistémica y evolucionista están llamadas a jugar un importante papel en el desarrollo de la ciencia y de la cultura modernas no solamente por su capacidad para servir como nexos interdisciplinares, sino para aportar ideas fértiles en las disciplinas concretas, tal como ocurre actualmente en disciplinas tan dispares como: economía, filosofía de la ciencia, evolución tecnológica, neurología, cosmología, etc. Sin pretender hacer transposiciones mecánicas, creemos que ambas concepciones pueden enriquecer el constructivismo en las tres perspectivas anteriormente indicadas. 


\section{MARCOS RACIONALES DE LA CIENCIA}

Las reglas de razonamiento establecidas por la lógica formal occidental siempre se utilizaron como criterios de demarcación entre el pensamiento primitivo y el del hombre occidental. Pero la antropología del siglo xx ha puesto de relieve que, al contrario de lo que se pensaba en la Europa del XIX, la racionalidad no es exclusiva de la civilización occidental, sino de cualquier cultura humana (Evans Pritchard, 1940; Lévi-Strauss, 1962; Latour, 1992). Por otra parte, numerosos filósofos de la ciencia (Kuhn, 1962; Feyerabend, 1970; Toulmin, 1972), señalan que, incluso en el santasanctorum de la racionalidad, la ciencia, existen componentes (presupuestos, intereses, valores, fines, etc.) que escapan a la lógica formal, única línea fronteriza entre la ciencia y otros tipos de conocimiento admitida por el positivismo.

Las culturas no son sistemas cerrados, es posible la comunicación intercultural hallando las claves de la racionalidad de las diferentes culturas. Dichas claves consisten en averiguar los presupuestos, comprender las formas de razonamiento y conocer los fines de cada cultura, en otras palabras, en determinar el marco racional cultural (Luffiego, 1997) que proporciona las principales reglas del juego de la racionalidad de cada cultura $\mathrm{y}$, al mismo tiempo, restringe su actividad y validez. Denominaremos marco racional cultural a este sistema racional general que determina una cosmovisión y que, aunque de manera implícita a veces, nos hace pensar, sentir, decidir y actuar de una manera determinada.

Nuestra cultura también posee su propio marco racional, extremadamente complejo, en el que dentro de ella juega un papel importante la ciencia. A pesar de que es difícil reconocer la existencia de transdisciplinariedad en las ciencias naturales modernas y de que, en más de una ocasión, estas ciencias, surgidas de la Revolución científica del s. XVII, han sido incapaces de mantener la unidad de la ciencia (Bertalanffy, 1968), a menudo se emplea, en diferentes contextos, el término genérico de ciencia, lo cual parece indicar que todavía se conserva un hilo de unidad.

Tras esta unidad subyace un marco racional científico que podemos denominar mecanicista (Luffiego, 1997), un sistema integrado por presupuestos, metodologías y fines, el cual cumple unas funciones sociales importantes: la predicción, el control de los procesos y la contribución al progreso social (Tabla I). Muchos componentes de este marco son implícitos pero no por ello dejan de actuar. A su vez, dentro de este marco, se han diferenciado diferentes disciplinas: física, química, biología y geología, y, dentro de éstas, diferentes subdisciplinas o ramas, teorías, que también poseen sus propios presupuestos, procedimientos y objetivos. Se trata, por lo tanto, de un sistema de sistemas.

Muy resumidamente (Tabla I), la ciencia mecanicista posee unos presupuestos ontológicos consistentes en creer que la realidad es una máquina desmontable y manipulable en la que reside linealidad, es decir, una proporcionalidad entre causas y efectos. En cuanto a los presupuestos epistemológicos se asume que la realidad es cognoscible tal cual a través del método científico (realismo ingenuo) y que es demostrable (positivismo o empirismo lógico). Junto a estos presupuestos se desarrolló una metodología simplificadora y reduccionista (Bertalanffy, 1968), uno de cuyos objetivos esenciales es expresar matemáticamente la realidad en forma de ecuaciones. Sobre todo así se pueden lograr los fines que ya Bacon (1627) explicitó y que fueron asumidos por las principales instituciones de la época (Royal Society, Academia Alemana, etc.), a saber: conocer y dominar la naturaleza para ponerla al servicio del hombre. Con el tiempo, la cultura del mecanicismo ha creado la ilusión colectiva del progreso indefinido basado en la posibilidad de obtener un conocimiento total y un control absoluto de la naturaleza (Mayer, 1998).

El impresionante edificio levantado por la ciencia mecanicista a lo largo de más de tres siglos, avalado por el desarrollo de múltiples innovaciones tecnológicas que han cambiado el mundo, no es suficiente para evitar que comiencen a aparecer en él ciertas tensiones. Después del infructuoso intento del positivismo de hacer de la ciencia un conocimiento seguro, de las múltiples críticas recibidas acerca de sus fundamentos epistemológicos por parte de los filósofos de la ciencia historicistas (Kuhn, Lakatos, Feyerabend...), del surgimiento de críticas antimecanicistas internas a las propias disciplinas, en concreto en el buque insignia del mecanicismo, la

Tabla I

Componentes del marco racional mecanicista.

\begin{tabular}{|l|l|l|l|}
\hline Presupuestos & \multicolumn{1}{|c|}{ Metodología } & Fines & Funciones \\
\hline $\begin{array}{l}\text { Ontológicos: } \\
\text { Realismo mecanicista }\end{array}$ & $\begin{array}{l}\text { Aproximación } \\
\text { analítico-parcelaria } \\
\text { Evolución lineal } \\
\text { y positiva (progreso) }\end{array}$ & $\begin{array}{l}\text { Conocer la naturaleza } \\
\text { formulación a da }\end{array}$ & $\begin{array}{l}\text { Predicción } \\
\text { Control de procesos } \\
\text { Contribución } \\
\text { al progreso }\end{array}$ \\
$\begin{array}{l}\text { Epistemológicos: } \\
\text { Positivismo } \\
\text { Realismo ingenuo }\end{array}$ & Reducccionista & & \\
\hline
\end{tabular}


física, con la noción de irreversibilidad termodinámica (Prigogine y Stengers, 1979), y del surgimiento de alternativas metodológicas diferentes en las disciplinas sociales e incluso en el seno de una misma disciplina (Jacob, 1970), como en la biología (piénsese en las metodologías tan dispares de la biología molecular y la ecología), el mecanicismo ha experimentado una crisis de entidad que ha hecho que cierta parte de la comunidad científica se haya manifestado en contra de la seguridad y dogmatismo científicos.

De más incidencia todavía ha sido la pérdida de legitimidad que ha tenido la ciencia entre el público en general, como consecuencia de cuestionarse su papel como garante del progreso indefinido y de extenderse la desconfianza en algunos de los avances que realiza: energía atómica e ingeniería genética (Alfonseca, 1999). Además, la naturaleza parece lejos de ser dominada. La crisis ecológica especialmente está cuestionando esta filosofía del progreso que en la práctica se traduce en la necesidad de crecer ilimitadamente (Luffiego et al., 1994b), tendencia propia de los procesos cancerígenos que comienza a producir más riesgos para el hombre que beneficios obtiene de él, con lo que el ideal baconiano se desinfla precipitadamente.

Sin embargo, las sociedades modernas necesitan una ciencia transformada que aborde la complejidad de los nuevos problemas, cumpla sus funciones de predicción y control de los fenómenos en la medida de lo posible y contribuya a formar unos ciudadanos críticos y conscientes sin los cuales las democracias no se pueden sostener.

La ciencia que se precisa ha de hacerse modificando el marco racional de la ciencia actual pero evitando caer en posiciones epistemológicas radicales e incluso extravagantes como las que han mantenido ciertos pensadores postmodernos y buena parte del movimiento constructivista radical y social, lo que ha provocado -no sin razónla reacción de importantes científicos en favor de la objetividad de la ciencia, como Sokal (1997) y Weinberg (1999), advirtiendo además que los beneficiarios de un relativismo extremo son las religiones, las sectas y las seudociencias. El caso de la enseñanza de la teoría de la evolución en el estado de Kansas es bien ilustrativo de hacia dónde puede conducirnos tal relativismo.

A continuación trataremos de definir este nuevo marco, que denominaremos marco racional de la complejidad (sistémico-evolutivo), y precisaremos cuál podría ser el papel del constructuvismo dentro del mismo.

\section{Los nuevos presupuestos ontológicos}

Desde la publicación de la Teoría general de sistemas (Bertalanffy, 1968), se ha abierto la posibilidad de ver la realidad como un sistema de sistemas. Los componentes de un sistema son a su vez subsistemas que interaccionan entre sí y como resultado de dicha interacción emergen propiedades que no son el mero resultado de la suma de las propiedades de las partes; así mismo, en un sistema desaparecen propiedades que estaban presentes en sus componentes.

Los avances en el estudio de sistemas dinámicos nos hacen asumir el presupuesto de que la evolución de los sistemas naturales y sociales es de naturaleza no lineal (aunque en ciertos momentos o en ciertos sistemas pueda ser lineal), y que aparecen en ella puntos de bifurcación que constituyen diferentes posibilidades de evolución del sistema (Prigogine y Stengers, 1979; Laszlo, 1987) (Tabla II).

\section{Los presupuestos epistemológicos}

Se asume que la realidad existe y que es cognoscible. Es cognoscible porque el aparato cognoscitivo humano es fruto de una evolución, de una interacción con la realidad, donde se ha ido ajustando a la misma, por lo que su producto, el conocimiento, no puede ser completamente falso (Vollmer, 1973; Ursúa, 1993); este presupuesto lo denominaremos realismo adaptativo (Luffiego, 1997). Adviértase que no se afirma que el conocimiento sea verdadero, sino que no puede ser completamente falso, porque de otra manera el aparato cognoscitivo no hubiera aparecido en el curso de la evolución biológica y cultural.

Lo dicho es, en apariencia, consistente con las tesis del constructivismo radical (Glasersfeld, 1991; Maturana, 1995; Ceberio y Watzlawick, 1998), según las cuales el conocimiento es construido activamente por el sujeto y posee una función adaptativa. El punto de desacuerdo, sin embargo, estriba en las conclusiones epistemológicas que se extraen, en las que se afirma que la realidad es construida por el sujeto, negándose así la objetividad del conocimiento (Glasersfeld, 1995; Maturana, 1995; Ceberio y Watzlawick, 1998) y relativizándose radicalmente todo tipo de conocimiento. Se sostiene que el conocimiento científico, al igual que otros tipos de conocimiento (religiones, astrología, etc.), es simplemente una construcción social.

$\mathrm{Si}$, como se afirma, el conocimiento pertenece al reino de la subjetividad tampoco sería posible la intersubjetividad y carecería de sentido hablar de constructivismo social. En efecto, caeríamos en la paradoja de la intersubjetividad, pues al fin y al cabo el simple acto de percibir una palabra, algo que procede de la realidad externa, también constituiría un acto subjetivo. Entraríamos así en un paisaje torrebabeliano que se contradice con la experiencia que tenemos y con las ya no tan recientes experiencias de comunicación con especies de primates (Gardner y Gardner, 1969; Premack, 1971).

Por el contrario, además de que la intersubjetividad es posible porque los humanos poseemos estructuras cognoscitivas compatibles, buena parte del conocimiento humano construido individual o socialmente es objetivo, posee una correspondencia con la realidad exterior, aunque dicha correspondencia no sea isomórfica o especular. El experimento de Tootel y otros (1988) prueba 
que durante el acto perceptivo hay objetividad: en estudios sobre la percepción en macacos hay una patente fidelidad entre la forma del objeto y el patrón de actividad nerviosa.

No negamos que la función de la cognición sea adaptativa, pero ello no implica, como asevera Glasersfeld (1991), que sea incompatible con la objetividad, con el descubrimiento de realidades ontológicas. Desde un punto de vista sistémico la evolución está plagada de emergencias, de aparición de características y funciones nuevas, y la cristalización de la ciencia es un hito que nos acerca a la objetividad.

Por otra parte, huelga decir que el conocimiento es una construcción individual y social y que las empresas científicas pueden estar al vaivén de la mentalidad e intereses de los diferentes grupos sociales de la época. Pero si bien el conocimiento es una construcción interactiva, individual y social, la realidad no lo es, se nos impone, nos determina en mayor medida que nosotros a ella. Como señala Weinberg, citado por Glanz (2000), «el ascenso a un ocho mil», también es una actividad cooperativa, requiere la colaboración de un cierto número de personas pero no por ello afirmamos que los hombres han construido la montaña.

Aceptada la objetividad, hay que señalar que no todos los conocimientos son igualmente objetivos, aunque la plasticidad interpretativa de la realidad posee unos márgenes bastante restrictivos (González et al., 1996). La realidad externa es interpretable de diversas formas (así se aprecia cuando se estudian diferentes culturas), pero no de cualquier manera, ya que tanto el componente lógico como el empírico imponen restricciones de las que depende, en ocasiones, la supervivencia. De ahí que gran parte del conocimiento humano sea una reconstrucción de la realidad (Ursúa, 1993).

Además del realismo adaptativo, aplicable a cualquier tipo de conocimiento humano, el conocimiento científico precisa de otro presupuesto epistemológico, tras quedar invalidado el realismo ingenuo debido al fracaso de la empresa positivista de demostrar la seguridad del conocimiento científico. Se trata del realismo hipotético (Campbell, 1959; Popper, 1972; Lorenz, 1973; Rield, 1983; Vollmer, 1983, 1987; Pacho y Ursúa, 1990; Ursúa, 1993), según el cual el conocimiento científico es provisional y falible, posee un carácter hipotético. Una posible objeción a nuestro planteamiento es cómo conciliar la existencia de un conocimiento objetivo con el presupuesto epistemológico del realismo hipotético. Esta objeción viene de confundir conocimiento objetivo con conocimiento seguro (Ursúa, 1993). El predicado hipotético muestra la inseguridad de todo nuestro conocimiento, incluido el científico, aceptando que el conocimiento es falible y provisional. El predicado objetivo indica la referencia y, aunque no podemos demostrar que ésta sea completamente verdadera, no renunciamos a la objetividad, pudiendo afirmar, sin embargo, que no es completamente falsa. El conocimiento objetivo es posible, aunque no esté garantizado y contenga hipótesis y presupuestos (Ursúa, 1993). Si definiéramos conoci- miento objetivo como aquél que no depende del sujeto de conocimiento, como se ha hecho desde posiciones positivistas, entonces no habría conocimiento, puesto que el conocimiento es un proceso interactivo: «no hay conocimiento de la nada ni conocimiento sin sujeto de conocimiento» (Bunge, 1981). Con este autor, definimos el conocimiento objetivo como aquél parcialmente verdadero (tiene referencia) e intersubjetivo (es invariante respecto del sujeto de conocimiento o, dicho de otra manera, cualquier sujeto aplicando ciertas reglas del juego científico, que no son eternas pero tampoco arbitrarias, lo puede comprobar, aunque dicha comprobación sea parcial y falible).

La ciencia, a pesar de sus defectos y de no haberse demostrado que sea un conocimiento seguro, es una emergencia del sistema de conocimiento humano y es el sistema más fiable de conocimiento que tenemos para aproximarnos a la realidad. Es sabido que, como seres humanos que son, los científicos poseen intereses y ambiciones que ejercen influencia en su labor científica y que la observación de los hechos está mediatizada por sus constructos teóricos, pero la ciencia posee un sistema interno de evaluación que no descansa ni en la autoridad ni en la democracia, sino que lo hace principalmente en criterios de validez explicativa y predictiva (Bunge, 1981; Agazzi et al., 1986). De acuerdo con ello, la ciencia posee foros de comunicación y de crítica, y procedimientos de comprobación que están a disposición de todos. Por otra parte, la tecnología desarrollada a partir de teorías, utilizada para bien o para mal, muestra su capacidad de interaccionar con el medio, lo cual es una prueba de la objetividad de los conocimientos y leyes científicas.

En resumen, un constructivismo asentado en estos presupuestos epistemológicos puede constituirse en la teoría del conocimiento de las ciencias de la complejidad (Tabla II).

\section{El cambio metodológico}

La metodología sistémica o transdisciplinar no niega la posibilidad de un conocimiento disciplinar, de hecho la aproximación analítico-parcelaria ha sido y será absolutamente necesaria para interaccionar cognoscitivamente con -y descifrar- la realidad. Piénsese, por ejemplo, en el cambio que supuso, para el estudio de la herencia, la simplificación del objeto de estudio a un carácter, introducido por Mendel. Pero la aparición de problemas de mayor complejidad y de problemas fronterizos ha obligado a la ciencia a buscar métodos sistémicos (Bertalanffy, 1968) que, sin cerrar vías de investigación desde la óptica de las disciplinas, construya conocimientos más generales y las articule en torno a un lenguaje común evitando así contradicciones y falsos dilemas y mejorando las posibilidades de acercamiento a objetos de estudio complejos (Morin, 1982). La habilidad de focalizar el estudio de distintos niveles sistémicos alternativamente es un requisito para captar la complejidad de los sistemas (Capra, 1996), la aparición de propiedades emergentes y para evitar la tentación reduccionista. 
Tabla II

Componentes del marco racional de la complejidad.

\begin{tabular}{|l|l|l|l|}
\hline Presupuestos & \multicolumn{1}{|c|}{ Metodología } & \multicolumn{1}{c|}{ Fines } & Funciones \\
\hline $\begin{array}{l}\text { Ontológicos: } \\
\text { Realidad sistémica } \\
\text { Evolución no lineal }\end{array}$ & $\begin{array}{l}\text { Sistémica (aunque no } \\
\text { niega la aproximación } \\
\text { analítico-parcelaria, } \\
\text { atiende a la complejidad }\end{array}$ & $\begin{array}{l}\text { Conocer la naturaleza } \\
\text { Principio } \\
\text { de precaución } \\
\text { Principio } \\
\text { de sostenibilidad }\end{array}$ & $\begin{array}{l}\text { Predicción } \\
\text { Control de procesos } \\
\text { Contribuir } \\
\text { a la sostenibilidad }\end{array}$ \\
$\begin{array}{l}\text { Epistemológicos: } \\
\text { Realismo adaptativo }\end{array}$ & Transdisciplinar & & \\
Realismo hipotético & No reduccionista & & \\
\hline
\end{tabular}

Hasta el momento, la metodología sistémica no ha tenido un desarrollo significativo dentro del mundo científico (Césarman y Estañol, 1994). Esperemos que con los nuevos conceptos matemáticos de complejidad, caos, no-linealidad, etc., el desarrollo de los ordenadores y la comunicación interdisciplinar, termine por atravesar el umbral de la disciplinariedad y pueda abordar problemas de naturaleza transdisciplinar (Tabla II).

\section{Los fines de la ciencia sistémica}

La ciencia es un conocimiento que, al igual que los demás, debe ser evaluado de acuerdo con el criterio del realismo adaptativo, criterio que debe ser prevalente sobre los de evaluación interna.

Se ha definido el proceso de conocimiento como una interacción entre el sujeto y la realidad. Desde una perspectiva evolutiva y constructivista, todo organismo no solamente posee la capacidad de conocer la realidad para anticiparse a ella sino de realizar acciones sobre el medio, que tratan de acomodarlo a la medida del organismo (Lewontin, 1995), de modo que, durante la citada interacción, hay una coadaptación organismo-medio (realismo adaptativo).

Ello es especialmente evidente en el caso humano. La propia formulación baconiana de los fines de la ciencia contempla esta doble vertiente del conocimiento al sostener que se trata de conocer la realidad para dominarla. Sin embargo, ya hemos visto la inviabilidad de este camino. Están en cuestión las propias funciones de la ciencia como institución social, por lo que también hay la necesidad de definir nuevos objetivos generales de la ciencia.

Para ello, hay que tener presente que tanto el sujeto (y su aparato cognoscitivo) como el medio son sistemas dinámicos no lineales, por lo que el conocimiento científico no puede ser concebido como inmutable (Mayer, 1998). Los sistemas complejos, no lineales, se caracterizan porque durante su evolución pueden atravesar por fases estables en las que las causas quedan amortiguadas y no conducen a efectos relevantes, y por fases inestables en las que pequeñas causas pueden conducir a grandes efectos. En las fases inestables hay una impredecibilidad sustancial, los cálculos teóricos yerran a causa de la ampliación de los pequeños errores iniciales (Crutchfield et al., 1986; Bergé et al., 1988; Luffiego et al., 1994a). He aquí una fuente de incertidumbre que explica, en parte, nuestra ignorancia. Verdad e ignorancia son dos características epistemológicas intrínsecamente ensambladas y compatibles entre sí, cuya síntesis viene recogida en el concepto anteriormente expuesto de realismo hipotético: hay buenas razones para creer que nuestro conocimiento es en buena medida verdadero pero no podemos demostrarlo.

Pero esta conciencia de nuestra ignorancia puede ser el comienzo de un nuevo principio (Ravetz y Funtovicz, 1989) que sustituya a la seguridad baconiana y mecanicista. A nuestro entender éste debe ser el principio de precaución, propio de la cultura de la sostenibilidad, según el cual antes de poner en marcha tecnologías hay que asegurar el control de sus efectos secundarios sobre el medio ambiente y la sociedad.

Sin embargo, el principio de precaución tiene un sentido muy limitado en una civilización cuyo leitmotiv es el crecimiento continuo que está arrastrando la ecosfera a la inestabilidad y aumentando la dosis de incertidumbre del conocimiento. Por ello, al mismo tiempo, hay que sustituir el principio de dominación baconiano, que subyace a esta ciega estrategia del crecimiento continuo, por un principio de sostenibilidad, de integración sostenible de las sociedades en sus ecosistemas (Luffiego y Rabadán, 2000), reconociendo que aquéllas son dependientes de éstos (Tabla II).

Es desde estos nuevos principios cómo la ciencia puede reconciliarse de nuevo con la sociedad y ejercer sus funciones de predicción y control, dado que éstas no dependen sólo de la potencialidad de la ciencia y la tecnología, sino también de la existencia de cierta estabilidad tanto del sistema social como del ecológico. El progreso, tal como se ha entendido hasta ahora, puede poner en cuestión la propia supervivenvia de la humanidad, por lo que la ciencia y la técnica deben ponerse al servicio de un futuro sostenible. 


\section{UN MODELO EVOLUCIONISTA DE APREN- DIZAJE CONCEPTUAL}

Tras haber bosquejado el marco racional en el cual trabajamos, abordaremos los problemas relacionados con el cambio conceptual y, en general, con el aprendizaje de conceptos y teorías científicas.

En el artículo pionero de Posner y otros (1982) acerca del cambio conceptual se transfiere la metáfora de este cambio en la historia de la ciencia al plano del aprendizaje individual, proponiéndose un doble mecanismo de aprendizaje: asimilación y acomodación o cambio conceptual. Ahora bien, estos autores no dan cuenta de cómo se produce el mecanismo de cambio conceptual, tan sólo hablan de las condiciones de dicho cambio. Numerosos autores han tratado de rellenar esta laguna con mayor o menor fortuna, tal como se puede leer en el artículo de Oliva (1999). Sin embargo a nuestro juicio faltan modelos que sean más sustanciales y que expliquen lo que Pascual-Leone (1980) llama la paradoja del aprendizaje. La citada paradoja nos remite al problema de la emergencia: ¿Cómo surgen las representaciones en nuestro cerebro? ¿Cómo se construyen conceptos complejos a partir de simples? El problema tiene enjundia porque afecta a las propias raíces de la construcción del conocimiento.

El gran biólogo Dobzhansky dijo en alguna ocasión que nada tiene sentido en biología si no es a la luz de la teoría de la evolución. Y, aunque ciertamente el problema del aprendizaje no es sólo un problema biológico, nunca se podrá dar una respuesta satisfactoria del mismo prescindiendo de la base neurológica y de los conceptos evolucionistas (Bunge, 1981). Es por ello que, tratándose de un problema complejo, debe abordarse desde una perspectiva transdisciplinar.

En diferentes ocasiones hemos formulado un modelo sistémico de evolución conceptual (Luffiego et al., 1991, 1994a) que trata de dar cuenta de la dinámica del conocimiento y concretamente de este problema de la emergencia aplicando conocimientos de la teoría de los sistemas dinámicos. Posteriormente se ha completado en otros trabajos (Luffiego, 1997, 1998) mediante la incorporación del esquema evolucionista al mismo.

Además de esta influencia transdisciplinar, el modelo también se nutre de otras disciplinas, en especial de la neurología. Tras la denominada década del cerebro (años noventa), no deberían elaborarse modelos de aprendizaje de conceptos al margen de los hallazgos de las neurociencias. Destacamos aquí algunos de ellos:

- La materia del aprendizaje son las conexiones sinápticas interneuronales; así se pueden formar colectivos de neuronas. El aprendizaje conlleva la modificación sináptica (hipótesis de Hebb), es decir, durante el mismo se forman nuevas sinapsis o se refuerzan las existentes. Los trabajos de Kandel y Hawkins (1992) confirman este hecho. En cada instante experimentamos cambios en nuestra arquitectura cerebral con modificación y actualización de conexiones sinápticas. Además, reciente- mente se ha descubierto que se continúan formando nuevas neuronas a lo largo de toda la vida (Kempermann y Gage, 1999).

- Los procesos de debilitamiento de las sinapsis por falta de su activación son lentos (Nieto-Sampedro, 1988, 1996), por lo que el olvido del conocimiento antiguo es también lento.

- Según Damasio (1994), los conocimientos no se retienen explícitamente en forma de mapas ni de imágenes visuales, auditivas, etc., antes bien se encuentran codificados en patrones de actividad, que él denomina representaciones disposicionales (desde nuestro punto de vista serían equivalentes a los esquemas, generados por conjuntos de neuronas del córtex que mantienen múltiples conexiones entre sí y que, a su vez, activan o disponen [de ahí el nombre de las mismas] a las neuronas de las cortezas primarias formándose representaciones rememoradas de distintos tipos, relativamente evanescentes [Damasio, 1994]). Este sistema que genera continuamente imágenes no vívidas se denomina sistema representacional.

- La codificación del conocimiento es dispersa, está distribuida en múltiples regiones del córtex. Baste señalar que la visión requiere la actividad de 32 regiones neurales (Zeki, 1992; Damasio, 1994). Además no existen centros especiales de integración de este conocimiento disperso, de ahí que poco a poco se abra paso la idea de que la integración tiene lugar en las vías neurales que comunican las distintas áreas, mediante un proceso de sincronización (Freeman, 1991; Zeki, 1992; Damasio, 1994; Fuster, 1997).

- El sistema representacional y el del lenguaje son autónomos aunque están comunicados. Tanto evolutiva como ontogenéticamente es anterior el sistema representacional al del lenguaje (Damasio y Damasio, 1992; Laplane, 2000). El lenguaje tiene tres funciones: además de permitir la comunicación y poseer un conocimiento compartido socialmente, facilita la memorización del conocimiento al reducir la complejidad de las representaciones (la palabra perro sintetiza numerosas representaciones de este objeto), con lo que se pueden conceptualizar (Marín, 1999), es decir, encadenar mejor los conocimientos, construir otros más abstractos y categorizar el conocimiento (Damasio y Damasio, 1992).

Aunque no es el momento aquí de extendernos en una explicación exhaustiva del citado modelo, haremos una síntesis del mismo enfatizando aquellos aspectos que pueden tener repercusiones en la enseñanza y el aprendizaje.

Antes de nada, definiremos cuatro términos que utilizaremos reiteradamente: conocimiento, representación, concepto y esquema. Conocimiento es toda información que es generada por nuestro cerebro o que queda retenida en él y que puede o no ser manifestada. Representación es una imagen rememorada, no vívida (las imágenes vívidas son las percepciones); el cerebro elabora representaciones continuamente, incluso cuando dormimos. 
Concepto es la expresión lingüística de una o varias representaciones. Esquema es el conocimiento memorizado, estable, que se activa para generar representaciones que promoverán comportamientos declarativos (ideas, preconcepciones, conceptos) y procesuales (operaciones de organizar, clasificar, seriar, inferir, etc.).

La diferencia que hay entre esquemas y representaciones estriba en que éstas son imágenes evanescentes generadas a partir de aquéllos, mientras que los esquemas son implícitos, estables y están inscritos en la memoria. (Tal es la situación que se da cuando escribimos un párrafo en el ordenador y lo borramos involuntariamente, después es prácticamente imposible rehacerlo con las mismas palabras, aunque el significado sea muy similar al anterior. El esquema que han generado las representaciones es el mismo, aunque las frases producidas a partir de éstas sean diferentes). Hay que indicar que también se emplea la expresión esquema conceptual para hacer referencia a un conjunto de conceptos jerárquicamente relacionados.

Por lo tanto, el término conocimiento, en el sentido que nosotros lo utilizamos, posee un significado que contiene el significado de esquema, representación y concepto.

La hipótesis principal del modelo sostiene que existen tres procesos que explican la dinámica del pensamiento $y$, por lo tanto, del aprendizaje de conceptos: generación de representaciones, selección y retención de algunas de ellas, y olvido del conocimiento antiguo (Luffiego, 1997).

\section{Generación de conocimientos}

El sistema nervioso no es un mero sistema que, como los ordenadores, procese información, sino que la genera continuamente (Changeaux y Dehaene, 1989; Fuster, 1997) (Fig. 1). Éste es un hecho que puede experimentarse individualmente mediante simple introspección: si nos percatamos, constantemente aparecen representaciones mentales en nuestro cerebro más o menos evanescentes. Evidentemente este proceso de generación depende de los esquemas de la memoria, es decir, de la activación de los patrones de actividad inscritos en los colectivos de neuronas, así como de la interacción con nuestro medio. Pero los conocimientos codificados de esta manera no poseen una localización concreta, antes bien se encuentran distribuidos en múltiples áreas (Anderson, 1992; Goldman-Rakic, 1992; Damasio, 1994; Montilla, 1995). Ello plantea una cuestión primordial: ¿cómo se integra esta información distribuida en áreas diferentes para formar representaciones coherentes?

Como se ha dicho anteriormente, no existen centros de integración, al parecer ésta se produce en las propias vías neurales que comunican las diferentes regiones del córtex, mediante un proceso de sincronización. ¿Pero cómo se produce tal sincronización? Desde la neurología no hay explicación de este problema, tan sólo se observan conexiones de entrada y reentrada entre las distintas áreas en las cuales se encuentra almacenado el conocimiento.
Sin embargo, la teoría de los sistemas dinámicos puede ofrecer una explicación plausible del proceso de sincronización que, como hipótesis de trabajo, tiene un valor al menos heurístico. En concreto, sostenemos, junto a otros autores (Skarda y Freeman, 1990; Freeman, 1991; Globus, 1992; Luffiego et al., 1991, 1994a), que el cerebro, y especialmente el sistema cognoscitivo, posee una actividad caótica. En palabras de Freeman (1991): «[...] el caos subyace a la capacidad del cerebro para responder de modo flexible al mundo exterior y para generar nuevos patrones de actividad, incluidos los que se experimentan como ideas originales». Según este autor, la generación de actividad aperiódica y autónoma en mamíferos, sin necesidad de que existan estímulos externos, es una señal de que el sistema es caótico. Experimentos realizados en invertebrados indican que la actividad normal de una neurona responde a una actividad caótica (Abarbanel et al., 1996).

Según nuestro punto de vista, junto a colectivos de neuronas, cuyas sinapsis se hallan estabilizadas y regularizadas y que corresponden a los conocimientos memorizados (esquemas), se activan sincrónicamente otros colectivos neurales, con sinapsis lábiles, que mantienen conexiones con los anteriores, generándose un comportamiento caótico conjunto. Tal comportamiento es susceptible de regularización al recibir una señal regular del campo perceptivo o de colectivos neurales estables y regulares, es decir, de conocimientos memorizados. En otros términos, lo que sucede es que este comportamiento caótico puede ser regularizado de maneras diferentes, generándose nuevos patrones de actividad coherente y regular, nuevos comportamientos regulares que psicológicamente se proyectan como representaciones mentales (Luffiego, 1997, 1998). Se trata, por lo tanto, de un proceso emergente. La conexión de estas representaciones con el lenguaje da origen a los conceptos y frases, lo cual contribuye a su estabilización y memorización.

Ahora bien, también puede ocurrir que el comportamiento caótico del conjunto no se resuelva en una regularización, sino que permanezca en el tiempo. Esta situación se percibe psicológicamente como un problema que puede ser también formulado mediante el lenguaje.

Por lo tanto, como tal sistema caótico, el sistema cognoscitivo puede atravesar por fases estables, cuando la nueva información es integrada sin excesiva dificultad en los esquemas ya memorizados, y por fases inestables, cuando la nueva información o la propia interacción entre los conocimientos existentes generan problemas.

Esta capacidad caótica confiere al sistema cognoscitivo una enorme versatilidad y adaptabilidad. Mientras que la parte estable se encuentra memorizada y es fundamental para el mantenimiento del sistema, la parte inestable lo es para dotar de versatilidad al sistema y hacerlo adaptativo. En efecto, el comportamiento caótico no implica un comportamiento aleatorio sino que en realidad encierra un número potencialmente inagotable de comportamientos regulares, aunque inestables. La posibilidad de ejercer un control sobre este comportamiento y de lograr com- 
portamientos coherentes y regulares es posible y ha sido simulada en diferentes tipos de sistemas caóticos (Solé y Manrubia, 1996; Güémez y Matías, 1996), incluidos modelos neurales sencillos (Abarbanel et al., 1996; Luffiego, 1997, 1998). Si su comportamiento fuera regular, el sistema cognoscitivo no tendría versatilidad alguna para adaptarse a los cambios del medio y si fuera completamente aleatorio, como mantienen Changeux (1983, 1992) y Changeux y Dehaene (1989), generaría tal variabilidad que le impediría tener una mínima estabilidad para ser viable.

\section{Selección de las variantes conceptuales}

Las representaciones generadas son sometidas a procesos de evaluación, tanto conscientes como inconscientes. En ocasiones, se ha de responder o tomar una decisión sin disponer de tiempo para hacer una evaluación racional. Previamente a los procesos de evaluación consciente, algunas de las variantes son eliminadas mediante una evaluación inconsciente que se realiza en función de las experiencias pasadas con fuerte carga emocional (Damasio, 1994). Dependiendo de la actividad, el tiempo disponible para la evaluación consciente es variable, ya que puede estar determinada por distintos factores: la entrada de información, la coherencia, el rigor, el cálculo de las consecuencias posibles, la inteligibilidad, la funcionalidad, los intereses, etc.

La selección individual puede dar paso a una selección social siempre y cuando sean comunicadas las representaciones generadas (Fig. 1). El lenguaje, según Damasio y Damasio (1992), contribuye a categorizar el mundo y a reducir la complejidad de las estructuras representacionales a una escala manejable, lo que le hace ser un sistema muy económico desde el punto de vista cognoscitivo. Así la palabra perro suple muchas de las representaciones de este objeto y puede ser ensamblada con otras facilitando sobremanera el pensamiento complejo. El razonamiento coherente y complejo se hace posible gracias al lenguaje. Los diferentes constructos «etiquetados lingüísticamente» se conectan entre sí: los conceptos en proposiciones, y las proposiciones en secuencias de proposiciones o argumentos (Bunge, 1980).

Ciertas posiciones constructivistas (Pozo, 1989; Pozo y Gómez Crespo, 1998) mantienen que existen mecanismos psicológicos diferentes para el aprendizaje asociativo -que tendría un carácter implícito- y para el constructivo -de carácter explícito-. Desde nuestro punto de vista, los procesos subyacentes a ambos tipos de aprendizaje son los mismos, consisten en procesos de generación y selección. Las diferencias estribarían en el tipo de esquemas que son activados, en las representaciones que son construidas y en el carácter más o menos consciente de los factores que intervienen en la selección. Cuando alguien se plantea un problema, su aparato cognoscitivo genera numerosas representaciones y no puede controlar cuándo ni cuál será la que prevalezca como solución. Este proceso de generación es incontrolado, tanto en músicos, pintores, científicos (así lo han relatado científicos como Einstein y Poincaré) como en cualquier persona en un contexto cotidiano. Mientras que en el caso del aprendizaje espontáneo (asociativo) se activan esquemas relativamente simples, en el caso de los creadores antes citados son activados esquemas más complejos y abstractos (esquemas abstractos, «racimos» de esquemas, esquemas algorítmicos y de ecuaciones, etc.), que, como resultado de los procesos de generación, darán origen a representaciones e hipótesis también de mayor complejidad. Así mismo, existen diferencias en los procesos selectivos: mientras en el aprendizaje implícito y cotidiano predominan factores inconscientes o escasamente autocríticos, en el aprendizaje constructivo lo hacen factores conscientes y críticos, de modo que en éste, y más en la construcción científica, el número de microciclos de generación-selección es más elevado que en el caso del aprendizaje asociativo o del pensamiento cotidiano. Además, en el aprendizaje constructivo y en la elaboración de la ciencia existe una evaluación externa y crítica después de haber sido comunicados los conocimientos en los foros adecuados para ello: exámenes y discusiones en el aula y congresos, publicaciones, etc., respectivamente. A nuestro entender estas diferencias son lo bastante considerables para diferenciar las dos modalidades de aprendizaje sin necesidad de recurrir a procesos diferentes.

\section{El aprendizaje y el olvido}

Hasta ahora se ha proporcionado una explicación plausible del proceso de pensamiento (Fig. 1) pero todavía no lo hemos hecho del aprendizaje. El propio pensamiento conlleva aprendizaje porque implica la activación de conocimientos y, como ya se ha dicho, eso refuerza las conexiones sinápticas de los colectivos neurales implicados. Ahora bien, la entrada de información genera nuevas representaciones, alguna de las cuales será seleccionada. Pero ello no es suficiente para que se produzca un aprendizaje estable; para que quede retenido el conocimiento debe activarse un cierto número de veces. Esta utilización puede ser meramente repetitiva o bien puede ser versátil. Si es esta última, se ponen en marcha nuevos procesos de generación-selección que posibilitan la aplicación de dicho conocimiento a otros contextos o el establecimiento de relaciones con otros conocimientos ya memorizados. La activación versátil del nuevo conocimiento aumenta la probabilidad de que quede fijado en la memoria.

Lo expuesto líneas arriba permite explicar con relativa sencillez el hecho de que buena parte de nuestro conocimiento sea implícito y de que existan, junto a esquemas previos muy consolidados, construcciones temporales que son propias de la situación.

Desde la perspectiva que venimos considerando, todo el conocimiento es implícito en mayor o menor medida, dado que se registra de manera disgregada en una miríada de colectivos y centros neurales, cuya integración es un proceso activo. La integración repetida consolida el conocimiento, estabiliza los esquemas, de modo que su activación posterior puede llegar a ser inmediata. Los conocimientos previos son muy estables porque han sido 
Figura 1

Diagrama del flujo del proceso del pensamiento. Hay un proceso de generación de representaciones como consecuencia de la interacción de la entrada de información con los esquemas memorizados. A continuación hay un proceso de selección de las mismas, antes de ser comunicadas, y posteriormente una selección social. El sistema generador de representaciones es retroalimentado continuamente desde los sistemas de selección del lenguaje y desde la sociedad.

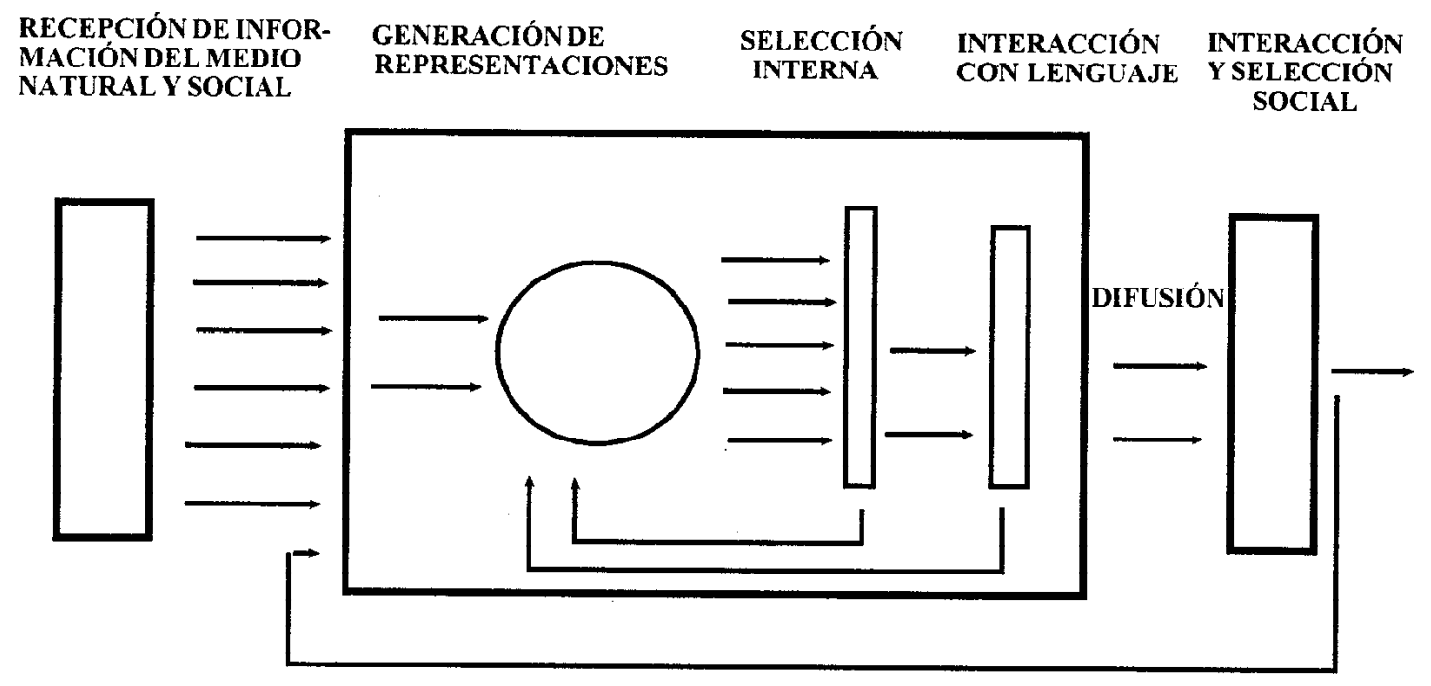

utilizados un gran número de veces en la vida cotidiana. Pero, a medida que se hace complexo el conocimiento, su activación es más prolija y requiere un mayor esfuerzo lingüístico. Definir el concepto perro es relativamente sencillo; sin embargo, recuperar y explicar el concepto evolución es más costoso. Puede ocurrir también que emerjan nuevas integraciones o asociaciones como resultado de situaciones nuevas para el sujeto (conocimiento situacional). Esto no es otra cosa que el resultado del proceso de pensar tal como se ha concebido éste anteriormente.

Paralelamente al refuerzo de algunas conexiones sinápticas, hay un proceso de olvido del conocimiento memorizado. Según Nieto-Sampedro (1996) hay tres formas de desconectar sinapsis: una de carácter voluntario, que consiste en que se debilitan por falta de activación; y otras dos de carácter involuntario, o bien por la interposición de expansiones gliales entre las sinapsis, o bien por un proceso espontáneo de degeneración sináptica y celular. Como señala este autor, cada vez es más evidente que existe una dinámica neural en la que están implicados procesos de formación y refuerzo de sinapsis junto a otros de degeneración sináptica.

Los conocimientos neurológicos proporcionan un fundamento para validar uno de los dos modelos de cambio conceptual. Permiten avalar el modelo de cambio conceptual por coexistencia y refutar, por el contrario, el modelo por sustitución. No es tanto por el hecho de que la nueva información precise para fijarse de la existencia de esquemas previos por lo que el modelo de coexisten- cia es el correcto (Marín, 1999), sino porque el olvido de los conceptos antiguos no es controlable por nosotros; este olvido es, generalmente, involuntario y lento y, por lo tanto, las ideas previas permanecen junto a los conceptos recientemente adquiridos. El valor pragmático y adaptativo del conocimiento cotidiano hace que se refuerce continuamente; las sinapsis implicadas son muy estables y, por lo tanto, difíciles de eliminar. Aunque desde otras perspectivas (Laudan, 1977; Solomon, 1988, 1994; Spada, 1994; Caravita y Halldén, 1994; Mortimer, $1995)$ se ha argumentado en favor del modelo de cambio conceptual por coexistencia, creemos que la neurología lo corrobora con datos, de momento, incuestionables. He aquí un ejemplo evidente de lo enriquecedora que puede ser la comunicación interdisciplinar.

De manera similar, los alumnos también poseen destrezas, actitudes, comportamientos e intereses previos, por lo que el aprendizaje de nuevas capacidades académicas requiere un período de coexistencia prolongado con aquéllas.

\section{Diferentes situaciones de enseñanza-aprendizaje}

El hecho de que admitamos la coexistencia no implica que entre el conocimiento cotidiano y el aprendido en la escuela no pueda haber interacción. A este respecto pueden darse las situaciones que se comentan a continuación.

Si no hay interacción, entonces se produce una compartimentación entre ambos tipos de conocimiento, no se establecen relaciones entre ellos ni en el ámbito de las 
Figura 2

En la compartimentación de conocimientos no existen relaciones en el campo teórico y no hay competencia en el campo de aplicación. El conocimiento A no se relaciona con el B y cada cual posee un campo de aplicación propio.

COMPARTIMENTACIÓN DE CONOCIMIENTOS
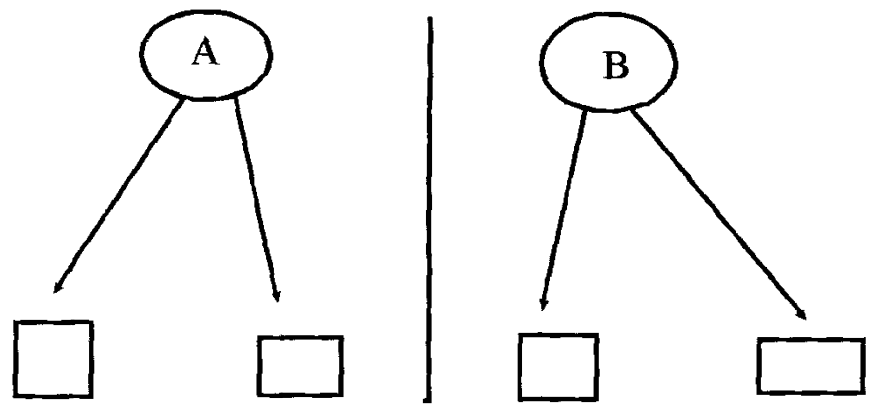

Campo teórico

Campo de aplicación

relaciones teóricas ni en el de la aplicación (Fig. 2). Es el caso de un alumno que aprende que «la fotosíntesis es un proceso de asimilación de dióxido de carbono y expulsión de oxígeno» manteniendo que «las plantas se alimentan del suelo», sin percatarse de que «es el sistema de alimentación que tienen las plantas».

De producirse interacción o activación conjunta, una primera modalidad es la integración (Fig. 3). En ella el conocimiento nuevo se integra en el esquema antiguo, aumentando su campo de aplicación; de esta manera tiene lugar el crecimiento (reestructuración débil) del esquema. Por ejemplo, el concepto previo de especie que aparece frecuentemente en los alumnos es el de «organismos que poseen un fuerte parecido entre sí», concepto que de ninguna manera entra en colisión con el científico, puesto que de hecho las tablas de clasificación se hacen basándose en las semejanzas y diferencias anatómicas. Esta peculiaridad permite un fácil enriquecimiento con la noción de organismos que se reproducen sexualmente, y la ampliación de su campo de aplicación a los casos de fuerte dimorfismo sexual.

Otra modalidad es cuando el conocimiento previo y el nuevo son incompatibles entre sí. Entonces se da una situación de coexistencia entre ambos, no hay relaciones

Figura 3

Durante la integración de conocimientos se establecen relaciones en el campo teórico. El sistema crece, evoluciona hacia un esquema más complejo que posee mayor capacidad de aplicación.

\section{INTEGRACIÓN DE CONOCIMIENTOS}

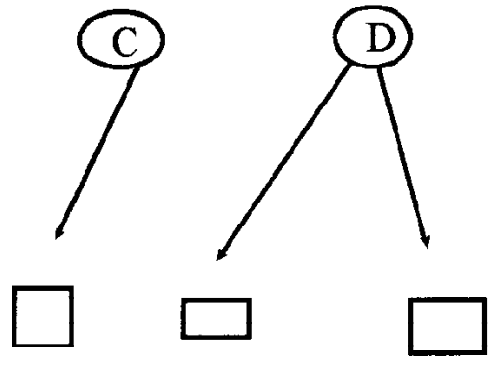

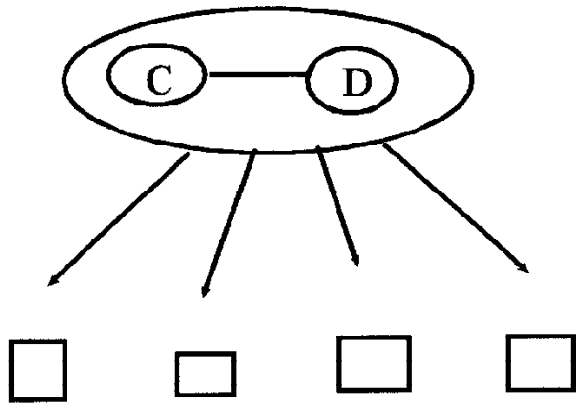

ENSEÑANZA DE LAS CIENCIAS, 2001, 19 (3) 


\section{INVESTIGACIÓN DIDÁCTICA}

desde el punto de vista teórico pero se produce competencia entre ambos en el campo de aplicación (Fig. 4). Los alumnos creen que «la absorción de los alimentos en el tubo digestivo se hace en función de si son buenos o malos». Tras comprender que «los venenos también se pueden absorber»y que «la absorción depende de si el tamaño de las moléculas es o no reducido», pueden darse las siguientes situaciones. Hay alumnos que saben aplicar sus representaciones correctamente en los distintos contextos (escolar y cotidiano) y saben transferir el concepto científico a situaciones cotidianas si se les pide hacerlo, lo cual es un signo de un buen aprendizaje. A medida que el concepto científico va creciendo en cursos posteriores, incorporando «los mecanismos de paso de moléculas a través de la membrana», el concepto científico se va consolidando, va ampliando sus relaciones y su campo de aplicación, mientras que el concepto previo puede llegar a extinguirse, en cuyo caso se habrá producido la sustitución (reestructuración fuerte) (Fig. 4). Sin embargo, también puede ocurrir que el concepto previo permanezca manteniendo su función cognoscitiva (Pozo, 1999).

Durante la coexistencia hay intentos de integración a pesar de la incompatibilidad lógica, como lo prueba el hecho de la existencia de conceptos resultantes (Hasweh, 1986), que, en la mayoría de los casos, son bastante inestables, responden a una situación y denotan un dominio del concepto previo sobre el científico. Así, después de la instrucción, algunos alumnos de BUP y LOGSE expresan, acerca de la absorción, que «se absorbe lo bueno y lo que sea de un tamaño lo suficientemente pequeño» 0 , en referencia a la excreción, algunos alumnos de $2^{\circ}$ y $3^{\circ}$ de medicina afirman que «las células expulsan desechos líquidos y sólidos, los líquidos se dirigen hacia la uretra y los sólidos se expulsan por el ano» (Luffiego, 1997). En este último caso, se intenta compaginar la idea científica de que las células expulsan desechos, con el concepto previo, fuertemente arraigado, de que los sólidos se expulsan por el ano y los líquidos por la uretra.

Otra posibilidad en la que puede desembocar la coexistencia es que, tras un período de coexistencia más o menos prolongado, el conocimiento científico no quede bien reforzado, o bien al no competir positivamente con el previo por el campo de aplicación, o bien al no proseguir su crecimiento. Entonces, no habrá sustitución, en cuyo caso, el conocimiento previo quedará reforzado. Este tipo de evolución que se da en algunos conceptos prevalece en la mayoría de los estudiantes y es la que explica el relativo fracaso de la enseñanza. La especialización no es más que el crecimiento del conocimiento en una rama del saber y su olvido paulatino en otros campos. Hay pocas personas que tengan tantos conocimientos y tan amplios como los buenos alumnos de COU o $2^{\circ}$ de bachillerato. Es probable que ningún profesor aprobara los exámenes de manera tan brillante a como lo hacen estos alumnos. Sin embargo, después de breves años de carrera, estos alumnos olvidan gran parte de su conocimiento.

¿Para qué, entonces, tomarse tantas molestias y enseñar cosas que se van a olvidar? ¿Para qué enseñar ciencia?, nos podemos preguntar con Pozo (1999).

La respuesta a esta pregunta es importante porque, además de interesar a los fines de la enseñanza de la ciencia, está en juego la transdisciplinariedad (García y Merchán, 1997). No olvidemos que en el curso del aprendi-

Figura 4

Cuando hay incompatibilidad entre el conocimiento previo (E) y el científico (F) se produce coexistencia, no hay relaciones en el plano teórico y hay competencia en el campo de aplicación. Con el tiempo se puede producir la sustitución, el conocimiento previo puede llegar a extinguirse por falta de activación, mientras el científico quedar reforzado, incrementando relaciones y ampliando su campo de aplicación.

\section{COEXISTENCIA DE CONOCIMIENTOS}
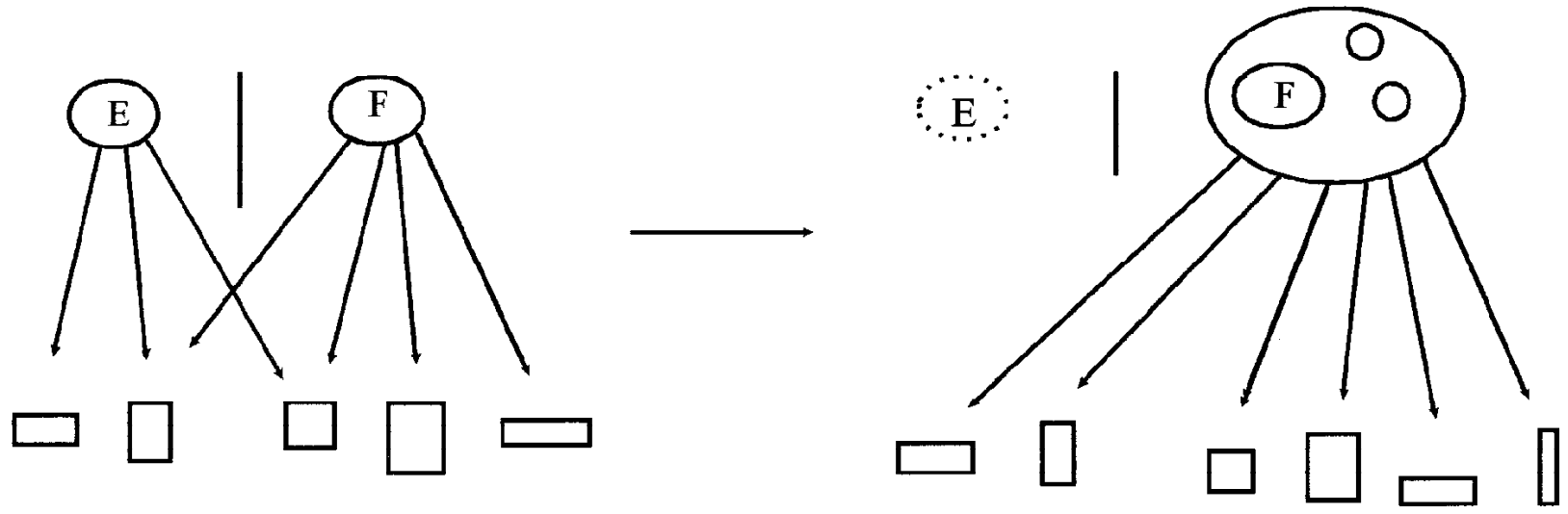
zaje, y paralelamente a la coexistencia, hay constantemente procesos de integración (crecimiento de los esquemas científicos) que implican la generación de representaciones cada vez más complejas y abstractas. Incluso, en el seno de una misma disciplina, aparecen estructuras que podemos denominar transcontextuales cuya investigación iniciada ya por Inhelder y Piaget (1955) y desarrollada y aplicada a la enseñanza de las ciencias por autores como Shayer y Adey (1981), Pozo y Gómez Crespo (1998), constituiría un paso intermedio y necesario para dotar de contenido a las concepciones transdisciplinares más generales: sistema, interacción, etc. Nos referimos, por ejemplo, a esquemas como la relación entre el incremento de superficie y la eficacia de los procesos de la nutrición (digestión, absorción, intercambio), o al esquema en el que están implicadas la interacción entre componentes de poblaciones y su descripción en términos de probabilidad (sea entre moléculas en reacciones enzimáticas, entre individuos en los temas de evolución y ecología...), o al de la conservación en física o en química. Estas estructuras de conocimiento posibilitan un pensamiento formal, dotado de formas de razonamiento, procedimientos, destrezas, esquemas analógicos que pueden ser transferidos a distintos contextos (Oliva, 1999). Aunque algunas investigaciones parecían indicar que los procesos de aprendizaje tenían más relación con los contenidos específicos que con la maduración del sistema cognoscitivo (Kuhn, 1979), investigaciones más recientes (Shayer y Adey, 1981; Acevedo et al., 1989; Gómez Crespo et al., 1995) vienen a mostrar que las estrategias cognitivas puestas en acción en contextos determinados pueden ser generalizadas a diferentes contextos, lo cual es indicativo de la adquisición de un pensamiento formal. En el supuesto anterior, aunque un buen alumno apruebe con mejores resultados los exámenes tradicionales que cualquier profesor, éste, seguramente, posee más capacidades para afrontar tareas como el diseño de una investigación o la preparación de una conferencia.

Después de lo expuesto, se puede comprender que es posible la sustitución de conocimientos incompatibles entre sí, pero tan sólo tras un largo período de activación de un conocimiento y lenta extinción de otro. La riqueza de interacciones vistas se refleja en la diversidad de concepciones que aparecen cuando se estudia una población de alumnos. Aunque parezca paradójico, con la instrucción aumenta la diversidad de variantes conceptuales (estimada mediante índices de diversidad aplicados en ecología), al menos durante el aprendizaje de algunos conceptos, en concreto, los conceptos relacionados con la nutrición (Luffiego et al., 1991; Luffiego, 1997). Sólo a partir de cursos universitarios, esta diversidad disminuye en favor de la estabilización de los conceptos científicos, lo cual es indicativo de que el cambio conceptual es muy lento (Luffiego, 1997). Este resultado empírico corrobora los argumentos antes expuestos.

Ahora bien, en ciertos contextos este cambio es aparentemente rápido. Cuando el aprendizaje va ligado a una fuerte experiencia emocional, entonces las nuevas conexiones resultan muy reforzadas en un breve lapso de tiempo. Por ejemplo, la experiencia de una guerra, de una enfermedad o la entrada en una secta pueden provocar fuertes cambios en los conocimientos, actitudes y valores en un tiempo relativamente breve.

\section{LA ENSEÑANZA DE LA CIENCIA}

A pesar de la inmadurez del modelo presentado, en el sentido de que no ha sufrido un proceso riguroso de experimentación práctica, cabe realizar ciertas consideraciones didácticas así como una crítica de las estrategias didácticas existentes.

Partiendo del modelo expuesto, se pueden distinguir tres vertientes didácticas que hay que atender y que permiten valorar los distintos modelos didácticos, así como diferenciar tres fases en el proceso de enseñanza-aprendizaje y de este modo caracterizar un modelo didáctico evolucionista: fase de problematización y selección, fase de retención por teorización y fase de retención por aplicación.

La fase de problematización y selección tiene la finalidad de incitar y dar la oportunidad a los alumnos de generar hipótesis, discutirlas y contrastarlas bibliográfica o experimentalmente. Esta fase es compatible con los diferentes modelos basados en la investigación de problemas (Furió y Gil, 1978; Gil, 1993; Porlán, 1993; Guisasola y De la Iglesia, 1997; Jiménez-Aleixandre, 1998; Gil et al., 1999).

Lo más atractivo de estos modelos es que, partiendo de un problema abierto, los alumnos formulan problemas cada vez más concretos e hipótesis referentes a ellos, y realizan diseños experimentales para su contrastación, con lo cual ejercen una labor que resulta motivante y contribuye al cambio procedimental (Furió y Gil, 1978; Gil, 1993; Gil et al., 1999).

La problematización/selección en el aula también puede llevarse a cabo mediante modelos de generación de conflictos cognitivos (Nussbaum y Novick, 1982; Driver, 1986, 1988; Cosgrove y Osborne, 1985; Pozo, 1989); por ejemplo, a partir de la exploración de ideas previas y su contrastación mediante cuestiones que pongan en contradicción a aquéllas. Este tipo de actividades originan debates en el aula e incluso sencillas investigaciones. Consideramos que el aprendizaje basado en la investigación de situaciones problemáticas abiertas es de mayor interés que el basado en estrategias de cambio conceptual o conflicto cognitivo, no tanto porque los alumnos se sientan frustrados al discutir y poner a prueba sus ideas (Gil et al., 1999) -extremo que en nuestra experiencia no hemos comprobado- como por abrir un escenario más favorable y autónomo para los procesos de problematización/selección; en otras palabras, para el ejercicio del pensamiento científico.

Para aprender significativamente es necesario pensar y comprender, pero no es suficiente. Además hay que retener los conocimientos. 
La segunda fase es la de retención por teorización. El aprendizaje es incompleto si no se atiende convenientemente esta vertiente. A través de una investigación, los alumnos pueden proponer y refutar hipótesis y extraer conclusiones, pero de ello a construir conceptos, relacionarlos y formularlos va un abismo. La conceptualización y teorización son procesos activos y difíciles de llevar a cabo porque el conocimiento está disperso y su compilación en palabras y frases ajustadas es ya de por sí una labor creativa complicada, máxime cuando hay carencias representacionales y de lenguaje, como en el caso de los alumnos. De igual modo ocurre en el campo de la investigación puntera. El propio Einstein decía que pensaba combinando imágenes mentales y que sólo, cuando reproducía una secuencia de su juego mental, se dedicaba de manera laboriosa a buscar palabras y símbolos para fijar y comunicar sus ideas (Pinker, 2000). De ahí que la mayor parte de la investigación que se realiza en el mundo no aporte enriquecimientos teóricos substanciales.

A las dificultades intrínsecas de conceptualización y teorización hay que añadir las derivadas de un medio informativo cada vez más repleto de imágenes. En este sentido, nos hacemos eco de las palabras de Sartori (1997) cuando advierte que la nueva cultura, basada primordialmente en el consumo de imágenes frente a la utilización de la palabra, puede traer consecuencias contraproducentes respecto a la capacidad de conceptualización y teorización de las nuevas generaciones de alumnos.

Por otra parte, tampoco hay que echar en saco roto la contribución de esta fase en el aprendizaje de procedimientos y destrezas cognitivas. Como dice Lewontin (1995): «[...] nuestros esquemas conceptuales condicionan no sólo las respuestas que damos a determinadas preguntas, sino también la formulación de aquellas preguntas que puedan ser interesantes». Por lo tanto, además de potenciar el rigor conceptual, la precisión terminológica y la capacidad para establecer relaciones, la adquisición de un cuerpo de conocimientos teórico capacita para el desarrollo del pensamiento hipotéticodeductivo y de estructuras transdisciplinares.

No vemos otra posibilidad de que los alumnos reconstruyan los conceptos y teorías científicos si no es a través de una fuerte intervención del profesor y mediante un laborioso esfuerzo individual. Esta opinión parece ir en contra de la corriente vygotskiana del momento que preconiza el trabajo en grupos (Gil et al.,1991; Kempa y Ayob, 1995). Nos parece que el trabajo en grupos puede ser positivo al someterse a contrastación las diversas hipótesis de los alumnos mediante la discusión o mediante diseños experimentales, y siempre y cuando el grupo funcione. Pero el aprendizaje, al fin y al cabo, es personal y es cada uno quien tiene que realizar el esfuerzo de comprender y memorizar, tareas que llevan su tiempo y dedicación.

Aunque la fase de retención por teorización no se olvida en los modelos investigativos (Gil, 1993; Gil et al., 1999), no se explicita suficientemente su importancia, con lo que quizá no se dedique a ella el tiempo necesario. En este sentido, creemos que hay que rescatar el valor que tiene la explicación (Ausubel et al., 1978), como lo proponen ciertos autores con el modelo de enseñanza por explicación y contrastación de modelos (Pozo y Gómez Crespo, 1998).

La tercera y última fase es la de retención por aplicación. Se trata del problema de la transferencia, de la aplicación del conocimiento científico adquirido a la resolución de problemas en otros contextos, incluido el cotidiano. La experiencia indica que dicha transferencia no es fácil de realizar. Los alumnos tienden a activar el conocimiento de la misma manera como lo han hecho en situaciones anteriores. Supone un esfuerzo para toda persona hacerlo en situaciones diferentes, ya que ello implica procesos de generación y de argumentación. Sin embargo, es una fase necesaria para el refuerzo de los conocimientos científicos adquiridos, dado que competirán entre sí el conocimiento antiguo y el nuevo, y si, como es de esperar, resulta más adecuado el nuevo, entonces se irá memorizando, mientras que el antiguo se irá debilitando lentamente.

A pesar de que en los últimos años se ha desdeñado la retención por repetición o memorización, creemos que en cierta manera hay que recuperar esta tarea, especialmente en determinados aprendizajes. Por poner un ejemplo, nuestra experiencia indica que, antes de abordar los conceptos fisiológicos relacionados con la nutrición humana, la memorización de los aspectos anatómicos más importantes y que se van a utilizar reiteradamente favorece el aprendizaje significativo y los alumnos ven en ella una tarea motivadora y académicamente rentable. La utilización de conceptos científicos requiere memorizar la etiqueta lingüística, tarea que no debe ser desdeñada, aunque sí dosificada, si pretendemos un avance en el aprendizaje científico.

Parece, pues, importante trabajar estas tres vertientes del aprendizaje de manera equilibrada. El problema es cuánto tiempo habremos de dedicar a cada una de ellas en función del tipo de alumnos que hay en el aula. Consideramos, como dice Pozo (1999), que no existe el Santo Grial didáctico, por lo que habrá que utilizar un modelo didáctico capaz de adaptarse a diferentes situaciones.

Un buen punto de partida es el modelo de investigación de situaciones problemáticas abiertas, pues, de todos cuantos hay, es el más cercano al que se defiende en estas páginas. No obstante, habrá que potenciar la fase de retención por teorización mediante la potenciación de actividades como el estudio de textos o la explicación del profesor. Ello requerirá más tiempo, problema que agobia a numerosos profesores. Una posibilidad para poder compatibilizar todas estas actividades es reducir -si no en todas, sí en algunas unidades didácticas- el tiempo dedicado a la fase de problematización/selección llevando a cabo tan sólo un contraste bibliográfico y prescindiendo del empírico. Dicho contraste bibliográfico se puede hacer incluso mediante textos seleccionados de antemano por el profesor. De esta manera, adaptando las actividades a poner en marcha en cada una de 
estas tres vertientes, se avanzará en el aprendizaje de conceptos, procedimientos y actitudes, de manera más efectiva y equilibrada.

Es, sin embargo, misión del profesor tomar decisiones relativas al diseño, la impartición y la evaluación de la instrucción en función del tiempo y los recursos disponibles, así como de la aptitud y actitud de los alumnos.

\section{REFERENCIAS BIBLIOGRÁFICAS}

ABARBANEL, H.D.I., HUERTA, R., RABINOVICH, M.I., RULKOV, N.F., ROWAT, P.F. y SELVERSTON, A.I. (1996). Synchronized Action of Synaptically Coupled Chaotic Model Neurons. Neural Computation, 8, pp. 1567-1602.

ACEVEDO, J.A, BOLÍBAR, J.P., LÓPEZ-MOLINA, E.J. y TRUJILLO, M. (1989). Sobre las concepciones en dinámica elemental de los adolescentes formales y concretos y el cambio metodológico. Enseñanza de las Ciencias, 7(1), pp. 27-34.

AGAZZI (1986) La fiabilidad de la ciencia. Investigación y Ciencia, 222, pp. 66-74

ALFONSECA, M. (1999). ¿Progresa indefinidamente la ciencia? Mundo Científico, 201, pp. 61-67.

ANDERSON, O.R. (1992). Some interrelationships between Constructivist Models of Learning and Current Neurobiological Theory, with Implications for Science Education. Journal of Research in Science Teaching, 29(10), pp. 1037-1058.

AUSUBEL, D.P., NOVAK, J.D. y HANESIAN, H. (1989). Psicología educativa. México: Trillas.

BACON, F. (1971). Nueva Atlántida. Madrid: Zero, SA.

BERGÉ, P., POMEAU, Y. y VIDAL, C. (1988). L'ordre dans le chaos. París: Hermann.

BERTALANFFY, L. VON (1976). Teoría general de sistemas. Madrid: FCE.

BUNGE, M. (1988). El problema mente-cerebro. Un enfoque psicobiológico. Madrid: Tecnos.

BUNGE, M. (1981). Materialismo y ciencia. Barcelona: Ariel.

CAMPBELL, D.T. (1959). Methodological suggestions from a comparative psychology of knowledge processes. Inquiri, 2 , pp. 152-182.

CAPRA, F. (1998). La trama de la vida. Barcelona: Anagrama.
Esta tarea adaptativa dependerá tanto de su experiencia como del conocimiento que tenga de la disciplina y de los procesos de enseñanza-aprendizaje y estrategias didácticas. Así pues, esperamos que éste y otros trabajos contribuyan no sólo a clarificar los supuestos teóricos de la enseñanza-aprendizaje sino a aportar conocimientos teóricos a los profesores para que tomen decisiones teóricamente fundamentadas en su trabajo.
CARAVITA, S. y HALLDÉN, O. (1994). Re-framing the problem of Conceptual Change. Learning and Instruction, vol. 4, pp. 89-111.

CEBERIO, M.R. y WATZLAWICK, P. (1998). La construcción del universo. Barcelona: Herder.

CÉSARMAN, E. y ESTAÑOL, B. (1994). El enigma de la relación mente-cerebro: cerebro y supervivencia. Ludus Vitalis, II(2), pp. 40-62.

COSGROVE, M. y OSBORNE, R. (1991). Modelos didácticos para cambiar las ideas de los alumnos, en Osborne, R. y Freyberg, P.(eds.).Elaprendizaje delas ciencias. Implicaciones de la ciencia de los alumnos. Madrid: Narcea.

CRUTCHFIELD, J.P., FARMER, J.D., PACKARD, N.H. y SHAW, R.S. (1986). Chaos. Scientific American, 225, pp. 46-57.

CHANGEAUX, J.P. (1983). L'homme neuronal. París: Fayard.

CHANGEAUX, J.P. y DEHAENE, S. (1989). Neuronal models of cognitive functions. Cognition, 33, pp. 63-109.

CHANGEAUX, J.P. (1992). Las neuronas de la razón. Mundo Científico, 127(12), pp. 717-725.

DAMASIO, A.R. y DAMASIO, H. (1992). Cerebro y lenguaje. Investigación y Ciencia, 194, pp. 59-66.

DAMASIO, A.R. (1996). El error de Descartes. Barcelona: Crítica.

DRIVER, R. (1986). Psicología cognoscitiva y esquemas conceptuales de los alumnos. Enseñanza de las Ciencias, 4(1), pp. 3-15.

DRIVER, R. (1988). Un enfoque constructuvista para el desarrollo del currículo en ciencias. Enseñanza de las Ciencias, 6(2), pp. 109-120.

EVANS-PRITCHARD, E.E. (1977). Los nuer. Barcelona: Anagrama. 
FEYERABEND, P. (1975). Contra el método. Barcelona: Ariel.

FREEMAN, W.J. (1991). Fisiología de la percepción. Investigación y Ciencia, 175, pp. 30- 38.

FUSTER, J.M. (1997). Redes de memoria. Investigación y Ciencia, 250, pp. 30-38.

GARCÍA, J.E. y MERCHÁN, F.J. (1997). El debate de la interdisciplinariedad en la ESO: el referente metadisciplinar en la determinación del conocimiento escolar. Investigación en la Escuela, 32, pp. 5-22.

GARDNER, R.A. y GARDNER, B.T. (1969). Teaching Sign Language to a Chimpanzee. Science, 165 (3894), pp. 664672.

GIL, D., CARRASCOSA, J., FURIÓ, C., y MARTÍNEZTORREGROSA, J. (1991). La enseñanza de las ciencias en la educación secundaria. Barcelona: Horsori.

GIL, D. (1993). Contribución de la historia y de la filosofía de lasciencias al desarrollo de un modelo de enseñanza-aprendizaje como investigación. Enseñanza de las Ciencias, 11(2), pp. 197-212.

GIL, D., CARRASCOSA, J., DUMAS-CARRÉ, A., FURIÓ, C., GALlEGO, R., GENÉ, A., GONZÁlEZ, E., GUISASOLA, J., MARTÍNEZ-TORREGROSA, J., PESSOA, A.M., SALINAS, J., TRICÁRIDO, H. y VALDÉS, P. (1999). ¿Puede hablarse de consenso constructivista en la educación científica? Enseñanza de las Ciencias, 17(3), pp. 503-512.

GLANZ, J. (2000). Steven Weingerg, físico del todo. El País, 9-2-2000

GLASERSFELD, E. VON (1991). Constructivism in Education, en Lewy, A. The International Encyclopedia of Curriculum. Oxford: Pergamon Press.

GLASERSFELD, E. VON (1995). Radical Constructivism: A way of knowing and learning. Londres: The Falmer Press.

GLOBUS, G.G. (1992). Toward a Noncomputational Cognitive Neuroscience. Journal of Cognitive Neuroscience, 4(4), pp. 300-310.

GOLDMAN-RAKIC, P.S. (1992). La memoria funcional y la mente. Investigación y Ciencia, 194, pp. 69-74.

GÓMEZ-CRESPO, M.A., POZO, J.I. y SANZ, A. (1995). Students'ideas on conservation of matter: effects of expertise and context variables. Science Education, 79(1), pp. 77-93.

GONZÁLEZ, M.I., LÓPEZ CEREZO, J.A. y LUJÁN, J.L. (1996). Ciencia, tecnología y sociedad. Una introducción al estudio social de la ciencia y la tecnología. Madrid: Tecnos.

GÜÉMEZ, J. y MATÍAS, M.A. (1996). Synchronization in small assemblies of chaotic systems. Physical Review E, 55(4), pp. 3059-3067.

GUISASOLA, J. y DE LA IGLESIA, R. (1997). Erein projektua: Proyecto de ciencias para la ESO basado en el planteamiento de situaciones problemáticas. Alambique, 13, pp. 83-93.

HASWEH, M.Z. (1986). Toward an explanation of conceptual change. European Journal of Science Education, 8(3), pp. 229-249.

INHELDER, B. y PIAGET, J. (1972). De la lógica del niño a la lógica del adolescente. Buenos Aires: Paidós.

JACOB, F. (1973). La lógica de lo viviente. Una historia de la herencia. Barcelona: Laia.
JIMÉNEZ-ALEIXANDRE, M.P. (1998). Diseño curricular: indagación y razonamiento con el lenguaje de las ciencias. Enseñanza de las Ciencias, 16(2), pp. 203-216.

KANDEL, E.R. y HAWKINS, R.D. (1992). Bases biológicas del aprendizaje y de la individualidad. Investigación y Ciencia, 194, pp. 49-57.

KEMPA, R.F. y AYOB, A. (1995). Learning from group work in science. International Journal of Science Education, 10(3), pp. 275-284.

KEMPERMANN, G. y GAGE, F.H. (1999). Regeneración de las células nerviosas en adultos. Investigación y Ciencia, julio, pp. 14-19.

KUHN, T.S.(1962). La estructura de las revoluciones científicas. México: FCE, 1975.

LAPLANE, D. (2000). Controversia: ¿Existe pensamiento sin lenguaje? Mundo Científico, 208, pp. 62-67.

LATOUR, B. (1992). Ciencia en acción. Barcelona: Labor.

LAUDAN, L. (1996). El progreso y sus problemas. Hacia una teoría del progreso científico. Madrid: Encuentro.

LAZSLO, E. (1988). Evolución: La gran síntesis. Madrid: Espasa Calpe.

LÉVY-STRAUSS, C. (1972). El pensamiento salvaje. México: FCE.

LEWONTIN, R.C. (1996). Genes, entorno y organismos, en Sacks, O. et al. (eds). Historias de la ciencia y del olvido. Barcelona: Siruela.

LORENZ, K. (1974). La otra cara del espejo. Ensayo para una historia natural del saber humano. Barcelona. Plaza y Janés.

LUFFIEGO, M., BASTIDA DE LA CALLE, M.F., RAMOS, F. y SOTO, J. (1991). Propuesta teórica y experimental de un modelo sistémico de evolución conceptual. Madrid: Centro de publicaciones del MEC.

LUFFIEGO, M., BASTIDA DE LA CALLE, M.F., RAMOS, F. y SOTO, J. (1994a). Systemic model of conceptual evolution. International Journal of Science Education, 16(3), pp. 305313.

LUFFIEGO, M., BASTIDA DE LA CALLE, M.F., RAMOS, F. y SOTO, J. (1994b). Epistemología, caos y enseñanza de las ciencias. Enseñanza de las ciencias, 12(1), pp. 89-96.

LUFFIEGO, M. (1997). «Diversidad y evolución conceptuales en nutrición humana. Un modelo sistémico-evolutivo del cambio conceptual». Facultad de Pedagogía. Universidad de Oviedo. Tesis doctoral inédita.

LUFFIEGO, M. (1998). ¿Pueden la teoría de la evolución, las neurociencias y la teoría del caos determinista contribuir a resolverel problema de cómo tiene lugar el cambio conceptual? en Banet, E. y De Pro, A. (eds.). Investigación e innovación en la Enseñanza de las Ciencias, pp. 85-95.

LUFFIEGO, M. y RABADÁN, J.M. (2000). La evolución del concepto de sostenibilidad y su introducción en la enseñanza. Enseñanza de las Ciencias, 18(3), pp. 473-486.

MARÍN, N. (1999). Delimitando el campo de aplicación del cambio conceptual. Enseñanza de las Ciencias, 17(1), pp. 80-92.

MARÍN, N., SOLANO, I. y JIMÉNEZ, E. (1999). Tirando del hilo de la madeja constructivista. Enseñanza de las Ciencias, 17(3), pp. 479-492. 
MATURANA, H. (1995). La realidad: ¿objetiva o construida? I. Fundamentos biológicos de la realidad. Barcelona: Anthropos.

MAYER, M. (1998). Educación ambiental: de la acción a la investigación. Enseñanza de las Ciencias, 16(2), pp. 217-231.

MONTILLA, P. (1995). Conocimiento, realidad, causas y fines desde la biología y las neurociencias. Madrid: Síntesis.

MORTIMER, E. F. (1995). Conceptual Change or Conceptual Profile Change? Science \& Education, 4, pp. 267-285.

MORIN, E. (1984). Ciencia con consciencia. Barcelona: Anthropos.

NIETO SAMPEDRO, M. (1988). Plasticidad sináptica. Investigación y Ciencia, 138, pp. 40- 49.

NIETO SAMPEDRO, M. (1996). Plasticidad neural: una propiedad básica que subyace desde el aprendizaje a la reparación de lesiones, en Mora, F. (ed.). Cerebro íntimo. Barcelona: Ariel.

NUSSBAUM, J. y NOVICK, S. (1982). Alternative Frameworks, conceptual conflict and accomodation: toward a principled teaching strategy. Instructional Science, 11, pp. 183-200.

OLIVA, J.M. (1999). Algunas reflexiones sobre las concepciones alternativas y el cambio conceptual. Enseñanza de las Ciencias, 17(1), pp. 93-107.

PACHO, J. y URSÚA, N. (1990). Razón, evolución y ciencia. Bilbao: Desclec de Brouwer.

PASCUAL-LEONE, J. (1980). Constructive problems for constructive theories: the current relevance of Piaget's work and a critique of information-processing simulation psychology, en Kluwe, R. y Spada, H. (eds.). Development model of thinking. Nueva York: Academic Press.

PINKER, S. (2000). La materia y el espíritu en el centro del debate. Mundo Científico, 209, pp. 38-39.

POPPER, K. (1974). Conocimiento objetivo: un enfoque evolucionista. Madrid: Tecnos.

PORLÁN, R. (1993). Constructivismo y escuela. Hacia un modelo de enseñanza-aprendizaje basado en la investigación. Sevilla: Díada.

POSNER, G.J., STRIKE, K.A., HEWSON, P.W. y GERTZOG, W.A. (1982). Accomodation of a scientific conception: toward a theory of conceptual change. Science Education, 66(2), pp. 211-227.

POZO, J.I. (1989). Teorías cognitivas del aprendizaje. Madrid: Morata.

POZO, J.I. y GÓMEZ CRESPO, M.A. (1998). Aprender y enseñar ciencia. Madrid: Morata.

POZO, J.I. (1999). Más allá del cambio conceptual: el aprendizaje de la ciencia como cambio representacional. Enseñanza de las Ciencias, 17(3), pp. 513-520.
PREMACK, D. (1971). Some General Characteristics of a Method for Organism That Do Not Ordinarily Acquire It, en Jarrad, L.E. (ed.). Cognitive Processes of Nonhuman Primates, pp. 47-82. Nueva York: Academic Press.

PRIGOGINE, I. y STENGERS, I. (1979). La nouvelle alliance. Métamorphose de la science. París: Gallimard.

RAVETZ, J. y FUNTOVICZ, R. (1989). Usable knowledge, usable ignorance. A discourse on two sorts of science, en InternationalConference:The experts are categorical: Scientific Controversies and Political Decisions Concerning the Environment. París.

RIELD, R. (1984). Evolución y conocimiento evolutivo: sobre la concordancia entre los órdenes del pensamiento y de la naturaleza, en Lorenz, K. y Wukettis, F.M. (eds.). La evolución del pensamiento. Barcelona: Argos Vergara.

SARTORI, G. (1998). Homo videns. La sociedad teledirigida. Madrid: Taurus.

SHAYER, M. y ADEY, P.A. (1984). La ciencia de enseñar ciencias. Madrid: Narcea.

SKARDA, C.A. y FREEMAN, W.J. (1990). Chaos and the new science of the brain. Concepts in Neuroscience, 1(2), pp. 275-285.

SOKAL, A. y BRICMONT, J. (1997). Fashionable nonsense. Postmodern intellectuals' abuse of Science. Nueva York: Picador USA.

SOLÉ, R.V. y MANRUBIA, S.C. (1996). Orden y caos en sistemas complejos. Barcelona: Universidad Politécnica de Catalunya.

SOLOMON, J. (1988). Una perspectiva social de los esquemas conceptuales. Investigación en la Escuela, 5, pp. 17-19.

SOLOMON, J. (1994). The rise and Fall of Constructivism. Studies in Science Education, 23, pp. 1-19.

SPADA, H. (1994). Conceptual Change or Multiple Representations? Learning and Instruction, 4, pp. 113-116.

TOOTEL, R.B.H., SWITKES, E., SILVERMAN, M.S. y HAMILTON, S.L. (1988). Functional anatomy of macaque striate cortex. II. Retinotopic organization. The Journal of Neuroscience, 8, pp. 1531-1568.

TOULMIN, S. (1977). La comprensión humana. I. El uso colectivo y la evolución de los conceptos. Madrid: Alianza.

URSÚA, N. (1993). Cerebro y conocimiento: un enfoque evolucionista. Barcelona: Anthropos.

VOLLMER, G. (1984). Mesocosmos y conocimiento objetivo: sobre los problemas que resuelve la gnoseología evolutiva, en Lorenz, K. y Wukettis, F.M. (eds.). La evolución del pensamiento. Barcelona: Argos Vergara.

WEINBERG, S. (1999). Una visión corrosiva del progreso científico. Mundo científico, 201, pp. 74-82.

ZEKI, S. (1992). La imagen visual en la mente y el cerebro. Investigación y Ciencia, 194, pp. 27-34. 